\title{
Evaluation of treatment response, drug resistance and HIV-1 variability among adolescents on first- and second-line antiretroviral therapy: a study protocol for a prospective observational study in the centre region of Cameroon (EDCTP READY-study)
}

Joseph Fokam ${ }^{1,2,3^{*}} \mathbb{D}$, Maria Mercedes Santoro ${ }^{4}$, Desire Takou', Anne-Esther Njom-Nlend ${ }^{5}$, Paul Koki Ndombo ${ }^{2,6}$, Nelly Kamgaing ${ }^{1,2,7}$, Cedric Kamta ${ }^{8}$, Andre Essiane ${ }^{9}$, Samuel Martin Sosso ${ }^{1}$, Alexis Ndjolo ${ }^{1,2}$, Vittorio Colizzi ${ }^{1,4}$ and Carlo-Federico Perno $1,4,10$

\begin{abstract}
Background: Sub-Saharan Africa (SSA) alone has nine out of every 10 children living with HIV globally and monitoring in this setting remains suboptimal, even as these children grow older. With scalability of antiretroviral therapy (ART), several HIV-infected children are growing towards adolescence (over 2.1 million), with the potentials to reach adulthood. However, despite an overall reduction in HIV-related mortality, there are increasing deaths among adolescents living with HIV (ADLHIV), with limited evidence for improved policy-making. Of note, strategies for adolescent transition from pediatrics to adult-healthcare are critical to ensure successful treatment response and longer life expectancy. Interestingly, with uptakes in prevention of mother-to-child transmission, challenges in ART programs, and high viremia among children in SSA, the success rate of paediatric ART might be quickly jeopardised, with possible HIV-1 drug-resistance (HIVDR) emergence, especially after years of paediatric ART exposure. Therefore, monitoring ART response in adolescents and evaluating HIVDR patterns might limit disease progression and guide on subsequent ART options for SSA ADLHIV.
\end{abstract}

Objectives: Among Cameroonian ADLHIV receiving ART, we shall evaluate the rate of immunovirologic failure, acquired HIVDR-associated mutations, HIV-1 subtype distribution, genetic variability in circulating (plasma) versus archived (cellular) viral strains, and HIVDR early warning indicators (EWIs) at different time-points.

(Continued on next page)

\footnotetext{
* Correspondence: josephfokam@gmail.com; fokamjoseph@circb.cm

${ }^{1}$ Chantal BIYA International Reference Centre for research on HIV/AIDS

prevention and management (CIRCB), Yaoundé, Cameroon

${ }^{2}$ Faculty of Medicine and Biomedical Sciences (FMSB), University of Yaoundé

I, Yaoundé, Cameroon

Full list of author information is available at the end of the article
}

(c) The Author(s). 2019 Open Access This article is distributed under the terms of the Creative Commons Attribution 4.0 International License (http://creativecommons.org/licenses/by/4.0/), which permits unrestricted use, distribution, and reproduction in any medium, provided you give appropriate credit to the original author(s) and the source, provide a link to the Creative Commons license, and indicate if changes were made. The Creative Commons Public Domain Dedication waiver (http://creativecommons.org/publicdomain/zero/1.0/) applies to the data made available in this article, unless otherwise stated. 


\begin{abstract}
(Continued from previous page)
Methods: A prospective and observational study will be conducted among 250 ADLHIV (10-19years old) receiving ART in the centre region of Cameroon, and followed-up at 6 and 12 months after enrollment. Following consecutive sampling at enrolment, plasma viral load and CD4/CD8 count will be measured, and genotypic resistance testing (GRT) will be performed both in plasma and in buffy coat for participants experiencing virological failure (two consecutive viremia $>=1000$ copies/ml). Plasma viral load and CD4/CD8 will be monitored for all participants at 6 and 12 months after enrolment. HIVDR-EWIs will be monitored and survival analysis performed during the 12 months follow-up. Primary outcomes are rates of virological failure, acquired-HIVDR, and mortality.

Discussion: Our findings will provide evidence-based recommendations to ensure successful transition from paediatrics to adult ART regimens and highlight further needs of active ART combinations, for reduced morbidity and mortality in populations of ADLHIV within SSA.
\end{abstract}

Keywords: HIV, Antiretroviral therapy, Adolescents, Cameroon

\section{Background}

Sub-Saharan Africa (SSA) alone carries $69.9 \%$ of the 36.9 million people infected worldwide and $65.8 \%$ of the 1.2 million the global AIDS-related deaths by end 2014, the majority occurring among adolescents [1]. With the highest burden of paediatric HIV infections (2.3 million), about nine out of every 10 children living with HIV found in the SSA region. With about $86.4 \%$ of the 220 , 000 newly infected children worldwide by end 2014 [1], the number of children living with HIV/AIDS will continuously increase overtime, thereby predicting a growing rate of adolescents living with HIV (ADLHIV) in this region. In this line, the burden of HIV/AIDS constitutes a continuous major threat for the future development of SSA countries, and therefore remains a leading poverty-related disease in the entire continent [1-3].

With the advent and scalability of Antiretroviral therapy (ART), there is a global decrease in AIDS-related deaths. Of note, 15.8 million people living with HIV were accessing ART as of June 2015, of which $67.7 \%$ were from SSA. Interestingly, about $94 \%$ of all children receiving ART are from SSA, a number expected to reach 1.5 million children by 2020 [1, 2]. In this context of continuous new HIV paediatric infections and increasing coverage in paediatric ART, the number of children living with HIV will increase, suggesting a higher likelihood of reaching adolescent age and even adulthood if treatment regimens remain fully effective in controlling HIV infection [2-4]. Most importantly, out of about three million children are living with HIV, an estimated 2.1 million were ADLHIV (10-19 years of age) in resource-limited settings (RLS) by end 2012, with a consistent rising of HIV-related deaths in these ADLHIV even though regressions are seen in other target populations (younger children, pregnant women, adults living with HIV/AIDS) [5]. ADLHIV therefore constitutes an HIV population with growing health concerns and with very limited findings for generalisable best practices specific to this target population, especially in SSA whereby, compared to the western world, there is persistent suboptimal monitoring strategies in routine practice [6-8].

With the increasing scale-up of ART, as high as $20 \%$ of children might experience virological failure (VF) in RLS, in the frame of high-levels of viremia generally observed in children. Moreover, as these children grow older, there are increasing risks of treatment failure associated to the development of HIV drug resistance (HIVDR), particularly with the limited therapeutic options available for clinical management $[7,8]$. Current paediatric first-line regimens consist of lamivudine, plus abacavir or zidovudine, plus ritonavir-boosted lopinavir (LPV/r) or nevirapine (NVP), depending on the motherchild pair's history of prevention of mother-to-child transmission (PMTCT) [6]. of note, LPV/r overcomes non-nucleoside reverse transcriptase inhibitor (NNRTI) resistance resulting from PMTCT exposure [2, 3, 9], while NVP matches with current postnatal prophylaxis $[3,8,9]$. The success of this lifelong paediatric treatment will largely depends on the effectiveness of the combination ART from childhood and monitoring overtime [8-14]. Current uptakes in PMTCT interventions and universal ART for children suggest that any infected child stands at high risk of transmitted or acquired HIVDR. Such risks are likely higher in a context whereby: (1) PMTCT practices have been varying overtime (from single dose nevirapine, AZT, to options $\mathrm{B}$ and $\mathrm{B}+$ ), (2) commonly available antiretrovirals are drugs with low genetic-barrier to resistance, (3) drug stock-outs are frequently reported and (4) poor adherence remains challenging. Furthermore, these factors are associated with clinical challenges of which the high viremia in children and the limited laboratory monitoring offer room for delayed detection of treatment failure with accumulation of HIVDR mutations at rates as high as $80 \%$ $[8,10,11,15-21]$. This situation limits therapeutic option as children grow older in SSA, thereby appealing for effective public health strategies for optimal sequencing of ART regimens, in order to maximise 
long-term treatment success and reduce AIDS-related morbidity and mortality in these RLS [8]. Most importantly, as older children require transitioning from pediatrics to adult ART regimens, sustaining longterm viral suppression prompts the need for reduced risks for mortality among ADLHIV in SSA [5]. With scarcity of evidence that reduces disease progression while preserving next therapeutic options for this growing population of individuals in SSA, there is need to implement an assessment that would guide efficient public health strategies in ART program performance for adolescents $[2,8]$.

As VF is generally associated with emerging HIVDR, assessing drug resistance mutations (DRMs), in the context of a failing regimen, provides clinical benefit and reduced mortality $[9,10,22]$. An evidence guiding selection of first- and second-line pediatric ART regimens, revealed an urgent need for alternative pediatric treatment options in RLS [23]. Furthermore, Kityo et al. in Uganda revealed high prevalence of pre-treatment HIVDR and a decreasing burden as children grew older ( $10 \%$ of all children versus $15.2 \%$ of children $<3$ years), implying that adolescents might have archived resistant strains after years of chronic infection [24]. Similar findings from East-Southern Africa reported high-levels of pediatric HIVDR, ranging from 29 to $77 \%$ based on PMTCT history, and decreasing rates of DRMs with increasing ages, thus confirming the fading-up of resistant strains over the fitness of wild-type species [11].

As aforementioned, DRMs fade-up as children grow older, and might remain occult in minority viral populations or in the cellular reservoirs [25]. For adolescents vertically infected with HIV, the mechanism of occult HIVDR might be driven by archiving in cellular reservoirs, due to the long-term chronic infection. Of note, our studies among children (aged 1-12 years) with wild type viruses revealed minority DRMs only at early age (1 year), supporting the fact that ADLHIV stand at higher chances of harbouring archived DRMs [26]. Of note, theseoccult resistant variants might remain hidden, ready to repopulate plasma from tissues/reservoirs under pharmacological pressure [11]. The potential presence and the eventual relevance of these minority variants in paediatric settings can be substantial, and merit attention in the frame of limited therapeutic regimens. Demonstrating the clinical implications of such archived DRMs remains an important unmet medical need [26]. In this light, assessing such archived DRMs among adolescents might provide complementary information with an added value for the sequencing of fully active ART combinations, and in turns increase their life expectancy.

When evaluating the efficacy of first- and second-line pediatric ART regimens in RLS, Boerma et al. reported the necessity to set-up salvage pediatric therapies that could be affordable options in RLS [23]. This entails an eventual need of newer second-line or third-line ART regimens. In this line, we earlier demonstrated the absence of major DRMs in the integrase region among ART-naïve, first- and second-line treated patients (including adolescents) in Cameroon, thus indicating a potential efficacy of integrase inhibitors (raltegravir, elvitegravir or dolutegravir) even in heavily treated patients [27, 28]. Furthermore, we also studied CXCR4 and CCR5 viral tropism to determine possible use of antiCCR5. Our data revealed high rates of X4-tropic viruses among Cameroonian patients, thereby suggesting poor outcomes of CCR5 antagonists (i.e. maraviroc) if used for a public health approach (i.e. without tropism testing) [27-30]. Most importantly, our data from next generation sequencing revealed R5-variants prevailing among children under five years old [26], with increasing proportions of X4-variants, in accordance with previous reports $[29,30]$. Thus, pending prospective investigations, a potential salvage ART regimen for adolescents failing ART might contained fully active reverse transcriptase inhibitors (RTIs) and/or protease inhibitors in combination with integrase inhibitor (raltegravir), as an affordable public health approach in RLS [14, 27, 28].

Within the SSA-settings, few studies have addressed the needs of ADLHIV. In South-Africa, a study comparing treatment outcomes between adolescents versus young adults at a public sector community-based ART revealed lower virological suppression rates and higher rates of VF among adolescents [31], thus underscoring the necessity for closer monitoring strategies and the eventual needs of subsequent salvage therapies [23]. In the Central African Republic, an assessment of virologic response and DRMs revealed 34\% of children in need of a second-line ART after first-line failure, while $47 \%$ of those under second-/third-line ART were experiencing VF with at least one major DRM to RTIs, thus calling for urgent need for improved pediatric ART and monitoring strategies. Among Cameroonian children (aged up to 12 years), we earlier reported high rates $(\sim 90 \%)$ at firstline failure, after a median-time-on-ART of about two years only. Second-line guided by sequencing data showed $\sim 70 \%$ with virological suppression and $\sim 90 \%$ with viremia less than 1000 copies/ml. HIV-1 diversity did not interfere with emerging DRMs and CD4 showed a poor sensitivity is predicting treatment response [18]. However, data on medium- to long-term follow-up are completely missing, and recent findings showed potential implications of genetic diversity on virological response, especially among CRF02_AG infected populations [32-35], with considerable programmatic challenges as in Cameroon $[36,37]$. While attempting to ascertain AIDS events among adolescents, Sharp et al. reported that, among vertically infected adolescents, the region of HIV-1-Gag 
targeted by CD8 $+\mathrm{T}$ cells as well as the magnitude of CD8+ response may have a clinical importance on monitoring disease progression [38]. With limited evidence in the management of ADLHIV in SSA, it would therefore be of great asset to thoroughly evaluate the immunovirologic response in this target population, in order to identify individual and programmatic factors to be tackled for improved quality of life and life expectancy among ADLHIV. Such analysis will help in tailoring treatment response, resistance profiling and adequacy to subsequent (second- or third-line) ART regimens for ADLHIV in need of newer therapeutic options in SSA.

The READY-Study (Resistance Evolution among Adolescents in Yaoundé and its surroundings) aimed at generating information towards improved recommendations for a successful long-term management of ADLHIV in SSA, with adequate and affordable transition policies from paediatric to adult ART regimens in these RLS. Among Cameroonian adolescents (1019 years old) receiving ART, we shall monitor the therapeutic response to first- and second-line regimens, drug resistance profiling and HIV-1 genetic variability during one-year follow-up. In this population of adolescents receiving ART in Cameroon, we shall: (1) Evaluate the rate of immunovirologic failure in the entire population at enrolment, month- 6 and month-12 follow-up points; (2) Evaluate acquired DRMs and HIV-1 subtype distribution among those experiencing VF at enrolment, month- 6 and month12 follow-up points; (3) Evaluate the genetic variability in circulating (plasma) versus archived (cellular) viral strains among those experiencing VF at enrolment, month-6 and month-12 follow-up points; (4) Evaluate HIVDR early warning indicators (EWIs), including survival analysis, in the entire study population through out the one-year monitoring period.

\section{Methods/design Study design}

A prospective and observational study will be conducted among ADLHIV receiving ART as per the national ART programme in Cameroon, with follow-up at 6 and 12 months after enrollment.

ADLHIV on ART will be enrolled from four health facilities in the centre region of Cameroon, consisting of:

- Two health facilities from the referral treatment centres (the Mother-Child Centre of the Chantal BIYA foundation and the National Social Welfare hospital, both in Yaoundé);

- Two health facilities from the management units (the Mbalmayo District Hospital in Mbalmayo and the Mfou District hospital in Mfou).
After enrolment (month-0), follow-up will be done at mid-point (month-6) and at end-point (month-12), assessing immunological and virological response, including HIV-1 genotypic resistance testing (GRT) in case of confirmed treatment failure.

\section{Description of study setting}

In Cameroon, a country with a generalised HIV epidemiology (4.3\% prevalence in the general population) and a broadly diverse HIV strains (with the prevailing CRF02_AG recombinant) [32-36, 39], the centre region is among sites with high HIV burden (6.1\%), and the locality of Yaoundé and its surrounding have a prevalence of $6.3 \%$ [40]. HIV prevalence among vertically infected children is still consistent (prevalence of 11.5\%) in the country [40], and 1.2\% of those aged 15-19 years are infected [39]. Altogether, these suggest a growing rate of ADLHIV in the country, with the centre region being among the most worrying. First-line ART regimens are widely used (96.3\%, consisting of two nucleoside RTIs [NRTIs] plus one non-NRTI [NNRTI]) and second-line ART regimens $(3.7 \%$, consisting of one protease inhibitor and two NRTIs) are also available nationwide, with a total of 122,638 people receiving ART by end 2013 [41]. The most used regimens for adult are zidovudine plus lamivudine plus nevirapine, followed by tenofovir plus lamivudine plus efavirenz, while for children zidovudine plus lamivudine plus nevirapine and zidovudine plus lamivudine plus efavirenz are predominant [41]. In terms of ART coverage by age range, $4 \%$ of treated patients are aged $0-14$ years versus $91 \%$ aged 15 and above (i.e. 5\% unknown age), and adolescents (i.e. aged 10-19 years) are distributed between these two groups [41]. Importantly, the highest coverage of ART is in the centre region (Yaoundé and its surrounding), followed by the Littoral and the North-west regions [41]. The national strategic plan targets $80 \%$ ART coverage of children age $0-14$ years by end 2015 [42], thus indicating a growing number of adolescents on ART.

The choice of the Centre region for the present study in Cameroon is therefore based on its high HIV burden, its high coverage of ART, the long-term experience in ART provision of health facilities [42], as well as the wide HIV-1 genetic diversity reported from vertically infected children and adolescents living in this geographical setting [18].

\section{Sampling method}

A consecutive and non-randomised sampling method will be used for participant enrolment, according to eligibility criteria. 


\section{Eligibility criteria}

Inclusion criteria Will be enrolled in the study ADLHIV (aged 10-19 years), who are receiving a first- or second-line ART for $\geq 6$ months in one of our study sites, who provide their written assent, whose legal guardian accept to provide a written informed consent (in addition to written assent provided by the adolescent), and irrespective of PMTCT antiretroviral history (exposed to PMTCT drugs, not-exposed to PMTCT drugs, or unknown exposure).

Non-inclusion criteria Will not be considered for enrolment ADLHIV not found (i.e. not formally registered) in the ART monitoring system of a study site, ADLHIV reported to be ART-naïve, to be on a drug regimen not included in the national guidelines, or to be on a structured treatment interruption.

Exclusion criteria Will be considered excluded from the study any participant who decides deliberately/freely to withdraw in the course of the study, or transferred out of a study site before mid- or end-point.

\section{Sample size}

Assuming the rate of VF at $40 \%$, a $95 \%$ confidence and $80 \%$ statistical power, sample size is 174 patients. Adding $10 \%$ potential LTFU during the one-year study period and $20 \%$ sequencing failure rate $[10,18]$, minimal sample size is 243 ADLHIV, rounded-up to 250 total sample size, further stratified into 150 ADLHIV in the referral centres (75 per site) and 100 in the HIV management units settings (50 per site), as per coverage in ART in these two geographical locations $[41,42]$.

\section{Sampling strategy}

All ADLHIV meeting study criteria will be invited for a written assent, as well as their legal guardians for a written informed consent. Fully consenting participants will be consecutively enrolled until complete sample size per site ( 75 for each of the two HIV referral centres and 50 for each of the two HIV management units). All participating ADLHIV will be consecutively assigned a unique ID number per site, and data will be centralised at the International Reference Centre Chantal Biya (CIRCB) for research on HIV/AIDS prevention and management in Yaounde, Cameroon. Physical and telephone contact details of participants will also be registered in the database for active follow-up, whenever necessary, by the study community-relay agents.

\section{Study procedures and variables Procedures and timeline}

Entire schedule requires 30-months overall: 6-months (month1-6) for administration/ethics/field preparedness, 6-months (Month 7-12) for enrolment of participants until complete sampling, 12-months monitoring (Month 7-24) for complete follow-up of one-year, and 6-months (Month 25-30) for closing study sites, data processing, and reporting. During enrolment (M0) at the clinic, study clinicians will obtain informed consent and participant assent from legal guardian and the ADLHIV, respectively, followed by collection of socio-demographic, clinical and economic data, HIV history (including date of HIV diagnosis and WHO-clinical staging), complete history of ARV (ART and/or PMTCT, previous viral load and $\mathrm{CD} 4 / \mathrm{CD} 8$ whenever available), as well as adherence levels. Intravenous blood $(6 \mathrm{ml})$ will be collected from each ADLHIV for laboratory analyses at the CIRCB. Practically, CD4/CD8 (cells/mm [3] and percentage) and plasma viral load (PVL) will be performed for all ADLHIV using flow cytometry and real-time polymerase chain reaction (PCR) respectively. Among those experiencing VF, RNA (from plasma) and DNA (from buffy coat) extracts, isolated using the QIAamp commercially available Viral RNA and DNA Mini Kit (QIAGEN), be will be used for PCR-amplification of the proteasereverse transcriptase (PR-RT) region of HIV-1. GRT will be performed on PR-RT amplicons using Sangersequencing, as previously described [43]. HIVDRassociated mutations will be interpreted using Stanford $H I V d b$ algorithm [18, 35, 36, 43]. GRT results will then guide the selection of effective ARVs available in the national ART programme (first-, second-, and third-line regimens) and outcomes (WHO-clinical staging, viral and CD4/CD8 measurements) will be measured at 6 and 12 month-visits.

Follow-up visits will be at mid-point (months Month 6 $[ \pm 1]$ ) and at endpoint (Month $12[ \pm 2]$ ) after enrolment into the study. At each time-point (baseline, mid-point and end-point), epidemiological and clinical data will be collected using the same procedure described above during enrolment (i.e. baseline), including ART-adherence assessment. $6 \mathrm{ml}$ of intravenous blood will be collected per visit (for CD4/CD8 and PVL). Among those experiencing VF at these visits, GRT will be performed as described above [18, 35, 36, 43], and the results will then guide the selection of effective ARVs available in the national ART programme for first-, second-, and thirdline regimens.

At each study phase (enrolment, midpoint, endpoint), residual samples will be stored at $-80^{\circ}$ available in the blood bank of the CIRCB. The entire work plan requires 30-months: 6-months (month1-6) for administration/ ethics/field preparedness, 6-months (Month 7-12) for enrolment of participants until complete sampling, 12months monitoring (Month 7-24) for complete followup of one-year, and 6-months (Month 25-30) for closing study sites, data processing, and reporting. 


\section{Detailed procedures}

At month-0, enrolment will be done at study clinic for all adolescents meeting study eligibility criteria. Participants will then be followed up during 12 months after enrolment, with scheduled visits at the clinic at months 6 ( \pm 1 month) and 12 ( \pm 2 month), for a total of 3 scheduled visits. Patients with virological failure (viral load $>1000$ copies $/ \mathrm{ml}$ ) at any timepoint will undergo an extra visit in the next 1 month with adherence support and to confirm the virological failure (VF) as aforedescribed. Participants' clinical management not considered in the study protocol will follow local recommendations for clinical practice at the discretion of the responsible physician.Procedures at Baseline visit (month 0). Mothers will be required to provide data contained in the Baseline Case Report Form (see clinical data definition below). Briefly, this will cover detailed epidemiological and clinical information, including socio-demographic and economic data, HIV history, history of antiretroviral usage by the adolescent, including drugs taken as part of PMTCT (if applicable), adherence to ART, and results from any laboratory test that were performed before study enrolment and available in the patient medical record file. Blood will be collected from each participating adolsecent, for a total of volumen $6 \mathrm{ml}$ per timepoint for the following: determination of: viral load $(600 \mu \mathrm{l}$ plasma); CD4/CD8 levels $(100 \mu \mathrm{l}$ whole blood); HIV-1 Sanger sequencing for protease-reverse transcriptase $(1000 \mu \mathrm{l}$ plasma for RNA extraction and $200 \mu \mathrm{l}$ buffy coat for DNA extraction); residual plasma samples will be stored at the biobank.

Laboratory procedures on sample management plans are provided below. Procedures at follow-up visits at months 6 and 12. Participants attending follow-up and their legal gauardians will be required to provide data contained in the follow-up Case Report Form, for updated information on epidemiological and clinical situation, with special emphasis on antiretroviral treatment information and HIV-related clinical events. Blood samples will be collected as described above. Similarly, for plasma viral load $>1000$ copies $/ \mathrm{ml}$, adherence support will be provide then GRT performed if and only if virological failure is confirmed one-month later.All laboratory analysis will all be performed at the International Reference Centre Chantal Biya (CIRCB) in Yaounde, Cameroon, among which: Viral load measurementsWill be performed using Abbott m2000rt, as per the manufacturer's instructions. Briefly, $600 \mu \mathrm{l}$ of plasma collected from EDTA tube is used for viral RNA extraction. Based on the principle of reverse transcription polymerization (RT-PCR), amplicons are generated from the RNA genome of HIV-1 in clinical specimens. An RNA sequence that is unrelated to the HIV-1 target sequence is introduced into each sample at the beginning of sample PCR mix preparation. This unrelated RNA sequence is simultaneously amplified by RT-PCR, and serves as an internal control (IC) to demonstrate that the process has proceeded correctly for each sample. The amount of HIV-1 target sequence that is present at each amplification cycle is measured using fluorescent-labeled oligonucleotide probes on the Abbott m2000rt instrument. The amplification cycle at which an increase in fluorescent signal is detected by the Abbott m2000rt is proportional to the log of the HIV-1 RNA concentration present in the original patient sample.CD4/CD8 will be performed using FACSCalibur, as per the manufacturer's instructions. Briefly, determination of lymphocyte subsets (CD3, CD4, CD8) will be performed on the flow cytometer (BD Biosciences, San Jose, CA) using a single-platform technology. A volume of $50 \mu \mathrm{l}$ whole blood will be stained with $10 \mu \mathrm{l}$ of Multitest reagent in Trucount tubes for $15 \mathrm{~min}$ (all from BD Biosciences), and red blood cells will be lysed by using fluorescence-activated cell sorting lysing solution (BD Biosciences). Data acquisition will be performed using CellQuest-Pro software (BD Biosciences) creating up to nine multicolor acquisition dot plots that use eight multicolor gates. Data will be then analyzed with FlowJo software version 7.5.5 for Microsoft (TreeStar, San Carlos, CA). Using Multitest reagents with Trucount tubes in the laboratory procedure, absolute subset count will be calculated with the following formula: (number of events in the region containing the cell population/number of events in the absolute count bead region) $\times$ (the number of beads per tube/test volume). If ncessary, a FACSCanto II (alternative platform to FACSCalibur) could be used for the same $\mathrm{CD} 4 / \mathrm{CD} 8$ measurement purposes. Briefly, these analyses will be performed using the FACS Diva software (BD Biosciences, San Jose, CA), by reading information from the BD FACSTM 7-color setup beads label into BD FACSCanto clinical software (2D barcode symbology), and also by reading coded patient information into a worklist. Sanger Sequencing for HIV-1 drug resistance testing will be performed for adolescent experiencing virological faiure, using ABI 3130xl (Genetic Anlyser with 16 capillaries), HIV genotyping will be performed using plasma samples and an in-house reverse transcriptase polymerase chain reaction (PCR) protocol, as previously described (Fokam et al., 2011). Briefly, RNA will be extracted from $140 \mu \mathrm{l}$ of concentrated plasma using the QIAamp Viral RNA minikit (Qiagen, Milan, Italy), according to the manufacturer's protocol. RNA extracts will then be retrotranscribed and amplified using the kit One-Step Invitrogen (Foster City, CA) (SuperScript One-Step for long templates RT-PCR) and 2 different sequence-specific primers for 40 cycles. For insufficiently amplified samples after the first round PCR, a second round PCR (semi- 
nested PCR) will be performed. A direct sequencing reaction will be done using 7-8 overlapping primers. For a full plate run, the sequencer of 16 capillaries will analyse 2 different patient samples simultaneously for $\sim 2.5 \mathrm{~h}$ per run, and assembly program (Seqscape v2.7) will be used for sequence analysis, and mutations will be interpreted following the Stanford HIVdb algorithm. Therefore, 12 samples will run for $15 \mathrm{~h}$ in total. Study timeline is provided as Additional file 1: (SDC) 1.

\section{Abstraction of HIVDR EWls}

Data on HIVDR EWIs will also be collected at each study phase, consisting of five variables among which $\mathrm{EWI}_{1}$ (on-time pill pick-up), $\mathrm{EWI}_{2}$ (retention in care), $\mathrm{EWI}_{3}$ (pharmacy stock-outs), $\mathrm{EWI}_{4}$ (dispensing practices), $\mathrm{EWI}_{5}$ (virological suppression). Among patients not retained in care during the 12-month follow-up period, we shall investigate to the underpinning reason that might be deliberate ART interruption, transfer out or mortality. Cases of mortality will then serve to determine the survival rate among the study participants.

\section{Definition of study variables}

- VF will be defined as two consecutive PVL $\geq 1000$ copies/ml within 1 month under intensive adherence counselling and support [10]. Participants with $\mathrm{PVL} \geq 1000$ copies $/ \mathrm{ml}$ at any visit will therefore undergo adherence counselling and extra-visit after 1 month to confirm or infirm VF.

- Immunological failure will be defined as persistent CD4 $<100$ cells/mm [3] during follow-up.

- Clinical failure will be defined as WHO clinical stage 3 or 4 events or death. Clinical management outside the study protocol will be done according to local national guidelines.

- HIVDR will be defined as the presence of any mutation, in the PR-RT regions of HIV-1, known to reduce the efficacy of NRTI, NNRTI or protease inhibitor, as per the Stanford HIVdb algorithm [18, 35, 36, 43].

- Good adherence will be defined as $\geq 95 \%$ compliance to ART (i.e. only one missing dose), measured by pill count and by self-reported, during the past 30 days.

- EWIs will be defined and their respective performance targets are provided below: $[10,3,8]$

\section{Quality assurance}

For each of the 3 study phases (enrolment, midpoint, endpoint), quality assurance will be performed by proficiency testing for PVL, CD4/CD8 (cell/mm [3] and percentage) and Sanger-based GRT.

\begin{tabular}{|c|c|c|c|c|}
\hline $\begin{array}{l}\text { EWI and } \\
\text { title }\end{array}$ & Definition & Numerator & Denominator & Target \\
\hline $\begin{array}{l}\mathrm{EWI} \\
\text { On-time } \\
\text { pill pick-up }\end{array}$ & $\begin{array}{l}\text { Proportion } \\
\text { of } \\
\text { adolescents } \\
\text { that pick-up } \\
\text { ART no } \\
\text { more than } \\
\text { two days } \\
\text { late at the } \\
\text { first pick-up } \\
\text { after the } \\
\text { baseline } \\
\text { pick-up. }\end{array}$ & $\begin{array}{l}\text { Number of } \\
\text { adolescents } \\
\text { picking-up } \\
\text { their ART } \\
\text { "on time" } \\
\text { at the first } \\
\text { drug pick-up } \\
\text { after baseline } \\
\text { pick-up date }\end{array}$ & $\begin{array}{l}\text { Number of } \\
\text { adolescents } \\
\text { who } \\
\text { picked-up } \\
\text { ARV drugs } \\
\text { on or } \\
\text { after the } \\
\text { designated } \\
\text { EWl } \\
\text { sample } \\
\text { start date }\end{array}$ & 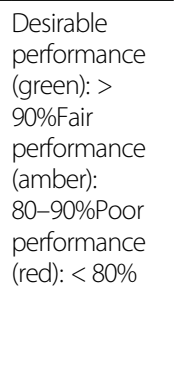 \\
\hline $\begin{array}{l}\mathrm{EWI}_{2} \\
\text { Retention } \\
\text { in care }\end{array}$ & $\begin{array}{l}\text { Percentage } \\
\text { of } \\
\text { adolescents } \\
\text { known to } \\
\text { be alive and } \\
\text { on ART } 12 \\
\text { months } \\
\text { after } \\
\text { enrolment }\end{array}$ & $\begin{array}{l}\text { Number of } \\
\text { adolescents } \\
\text { who are still } \\
\text { alive and } \\
\text { on ART } \\
12 \text { months } \\
\text { after } \\
\text { enrolment }\end{array}$ & $\begin{array}{l}\text { Total number } \\
\text { of adolescents } \\
\text { (excluding } \\
\text { transfers out) } \\
\text { who were } \\
\text { expected to } \\
\text { achieve } \\
\text { 12-month } \\
\text { outcomes }\end{array}$ & $\begin{array}{l}\text { Desirable } \\
\text { performance } \\
\text { (green): } \\
>85 \% \text { Fair } \\
\text { performance } \\
\text { (amber): } \\
75-85 \% \text { Poor } \\
\text { performance } \\
\text { (red): }<75 \%\end{array}$ \\
\hline $\begin{array}{l}\mathrm{EWl}_{3} \\
\text { Pharmacy } \\
\text { stock-outs }\end{array}$ & $\begin{array}{l}\text { Percentage } \\
\text { of months } \\
\text { in the study } \\
\text { period in } \\
\text { which there } \\
\text { were no } \\
\text { ARV drug } \\
\text { stock-outs }\end{array}$ & $\begin{array}{l}\text { Number of } \\
\text { months in } \\
\text { the designated } \\
\text { year in which } \\
\text { there were } \\
\text { no stock-out, } \\
\text { days of any } \\
\text { ARV drug } \\
\text { routinely } \\
\text { used at } \\
\text { the site }\end{array}$ & $\begin{array}{l}12 \text { months } \\
\text { of the } \\
\text { reporting } \\
\text { period }\end{array}$ & $\begin{array}{l}\text { Desirable } \\
\text { performance } \\
\text { (green): } \\
\text { 100\%Poor } \\
\text { performance } \\
\text { (red): < 100\%; }\end{array}$ \\
\hline $\begin{array}{l}\mathrm{EWI}_{4} \\
\text { Pharmacy } \\
\text { dispensing } \\
\text { practice }\end{array}$ & $\begin{array}{l}\text { Percentage } \\
\text { of } \\
\text { adolescents } \\
\text { being } \\
\text { dispensed a } \\
\text { mono- or } \\
\text { dual-ART }\end{array}$ & $\begin{array}{l}\text { Number of } \\
\text { adolescents } \\
\text { who pick up } \\
\text { from the } \\
\text { pharmacy, } \\
\text { a regimen } \\
\text { consisting } \\
\text { of one or } \\
\text { two ARVs; }\end{array}$ & $\begin{array}{l}\text { Number of } \\
\text { adolescents } \\
\text { picking up } \\
\text { ART on or } \\
\text { after the } \\
\text { designated } \\
\text { EWI sample } \\
\text { start date }\end{array}$ & $\begin{array}{l}\text { Desirable } \\
\text { performance } \\
\text { (green) defined } \\
\text { as 0\% } \\
\text { adolescents } \\
\text { picking-up a } \\
\text { mono- or dual- } \\
\text { ARTPoor } \\
\text { performance } \\
\text { (red) defined } \\
\text { as }>0 \% \\
\text { adolescents } \\
\text { picking-up a } \\
\text { mono- or } \\
\text { dual-ART, and }\end{array}$ \\
\hline $\begin{array}{l}\mathrm{EWI}_{5} \\
\text { Virological } \\
\text { suppression }\end{array}$ & $\begin{array}{l}\text { Percentage } \\
\text { of } \\
\text { adolescents } \\
\text { receiving } \\
\text { ART of ART } \\
\text { whose viral } \\
\text { load is } \\
<1000 \\
\text { copies } / \mathrm{ml} \\
12 \text { months } \\
\text { after } \\
\text { enrolment }\end{array}$ & $\begin{array}{l}\text { Number of } \\
\text { adolescents } \\
\text { receiving } \\
\text { ART } 12 \\
\text { months } \\
\text { after study } \\
\text { enrolment } \\
\text { and whose } \\
\text { viral load is } \\
<1000 \\
\text { copies } / \mathrm{ml}\end{array}$ & $\begin{array}{l}\text { Number of } \\
\text { adolescents } \\
\text { who have a } \\
\text { viral load } \\
\text { performed at } \\
12 \text { months } \\
\text { after } \\
\text { enrolment }\end{array}$ & $\begin{array}{l}\text { Desirable } \\
\text { performance } \\
\text { (green): } \\
>85 \% \text { Fair } \\
\text { performance } \\
\text { (amber): } \\
70-85 \% \text { Poor } \\
\text { performance } \\
\text { (red): }<70 \%\end{array}$ \\
\hline
\end{tabular}

\section{Management of potential study risks}

Lost to follow-up (LTFU) is a potential risk in reducing the power of this study for evidence-based recommendations. 
To limit LTFU, adherence support will be intensified and the site community relay agents will undertake active search of defaulters.

Investigators' compliance may be concerning at certain points of the study (i.e. if a collaborator moves for several reasons). To handle this potential challenge, site visit will be conducted weekly and site compliance to study regulations will be assessed by monthly supervision. The lead applicant will regularly coordinate activities with studysite clinicians and with guidance from mentor.

Data protection and safety might be concerning. This will be handle by procurement of a new computer device and a specific database dedicated exclusively for the project, with encrypted password and a protected working station. Potential bias in laboratory data will be handled with quality assurance. To ensure functionality of equipment, routine preventive maintenance will be ensured. If for any unforeseen reason an equipment breakdown, the backup laboratory (Centre Pasteur du Cameroun) will covered the required period, under current agreement. For staff protection, biosafety will be ensured by use of personal protective equipment as per international standards, including use of for a biosafety level II cabinet for project related-laboratory activities.

\section{Data collection and analysis}

Data will be collected per site and stored in a passwordprotected database at the CIRCB, Yaoundé-Cameroon, whereby the project statistician will coordinate data management and analyses using SPSS software. Study data will consist of sociodemographic, clinical and laboratory information. Data Management will be under the responsibility of the project Biostatistician of the CIRCB in Younde-Cameroon, in coordination with the principal investigator. Data management will therefore entail procedures for sociodemographic, clinical and laboratory data collection, data protection, data quality assurance and data analysis. This procedure will be similar at enrolment (M0), midpoint (M6) and endpoint (M12). Standardized Case Report Forms (CRFs) will be generated and provided to the four study sites for onsite collection of data. In addition to basic demographic information, CRFs will include all clinical information, as well as information on type of sample collected, including date, number of aliquots, volume of aliquots and sample identification numbers to reassure further tracing of laboratory results. CRFs will be translated and provided in French and in English as per national regulations in Cameroon. However, mainly the French version will be used as the study sites are all within the French-speaking sector of the country. CRFs will be completed by the project site collaborator, and doublechecked by a research fellow for consistency, if necessary, the CRF will be correctly completed and signed by the site principal investigator or other authorised person. At the end of each study visit, double-checked and signed CRFs will be sent to data entry. Laboratory CRFs will be also generated and provided in paper to the corresponding local laboratories to introduce laboratory results, together with identification number of samples. At the completion of laboratory procedures, laboratory project staff will be responsible for completion of laboratory CRFs, which will be double-checked by the coinvestigator for laboratory analyses and, if necessary, the CRF will be correctly completed and signed by the site principal investigator or other authorised person. At the end of this process, double-checked and signed laboratory CRFs will be sent to data entry.Data collected through clinical and laboratory CRFs will be entered on site through double entry, by designated data entry personnel. A specific database will be created for the protected entry of clinical data and laboratory results. Data storage will be done in numerical codes generated consecutively per site. Samples for plasma viral load, $\mathrm{CD} 4 / \mathrm{CD} 8$, and eventually for genotypic resistance testing (in case of treatment failure) to be daily centralised for analysis at the CIRCB laboratory, using participant anonymous ID code for their respective sample, alongside the corresponding sample transportation form. The laboratory co-investigator at CIRCB or other authorized person will have full responsibility for the completion of any procedures.

At enrolment, midpoint and endpoint, prevalence of VF and HIVDR (with 95\% Confidence Intervals) will be described globally, by geographical settings and by site. Associated factors will be evaluated using multivariate logistic regression, with an estimative approach for the unbiased effect of ART regimens (first versus secondline) and HIV-1 diversity (CRF02_AG versus nonCRF02-AG) [18]. In order to provide the highest level of evidence amongst ADLHIV experiencing VF versus those on virological success, ART response will be described through time to event data analysis and mixed models for the trajectory of CD4 count and viral load, based on adjustments of baseline confounders (duration of treatment, age, gender, orphan hood, site). The effect of DRMs (from plasma versus buffy coat) on ART response will be evaluated using multivariate survival models, either Cox or Fine\&Gray in the presence of death as competing event. Characteristics of patients LTFU will be described and, if necessary, inverse probability weights will be used. Primary outcome is the proportion of VF; secondary outcome is the proportion of acquired-HIVDR, or deaths, evaluated according to study site (referral centres versus management units), HIV-1 subtype distribution (CRF02_AG versus nonCRF02-AG) [18], adherence levels (<95\% vs. $\geq 95 \%)$ [44], and ART regimens (first versus second-line) [35]. 
Proportion of adolescents with low-level viremia ( $\geq 400$ or $\geq 50$ copies $/ \mathrm{ml}$ ) who finally end in VF will be described, along with HIVDR profile at endpoint [45]. We will build a multivariate logistic model with predictive approach to evaluate the association of socioeconomic conditions with adherence levels and HIVDR emergence [44, 46].

\section{Discussion}

Our research objectives will help in generating evidence for optimal monitoring and management of adolescents treated with antiretroviral therapy (ART) in a subSaharan African (SSA) context. Specifically, study objective 1 will help in understanding the significance of treatment failure among adolescents living with HIV (ADLHIV) in a resource-limited setting (RLS), will provide relative time-estimates for treatment failure, and propose locally affordable measures to limit ART failure in ADLHIV; study objective 2 will provide the burden of drug resistance according to the national treatment guidelines, and would inform on the adequacy between detected mutations and the most potentially active second- or third-line drugs for ADLHIV in such RLS. This study objective is inform if the development of HIVDR are specific to the different local HIV-1 clades, for possible clinical considerations for a specific management of adolescents in the country; study objective 3 will inform on the potential compartmentalisation of HIVDR among adolescents, in order to design drug combinations that provide maximal efficacy in a long run; study objective 4 will identify both programmatic factors favouring HIVDR emergence among ADLHIV, among which events of ARV stock outs and the quality of dispensing practices. This same objective will also identify the level of adherence of ADLHIV to ART, among which non-observance, delay drug pick-up and lost to followup. Importantly, with the exception of settings where HIV-1 subtype C prevails (found mainly in Southern Africa), our study impacts could be generalizable to the population of ADLHIV in several RLS, giving potential endorsements by national and international health regulatory bodies such the World Health Organisation (WHO) and UNAIDS.

\section{Additional file}

Additional file 1: Supplementary digital contents (SDC). SDC 1: Overal summary of major timeline and activities. (DOCX $29 \mathrm{~kb}$ )

\section{Abbreviations}

ADLHIV: Adolescent living with HIV; AIDS: Acquired immunodeficiency syndrome; ART: Antiretroviral therapy; ARV: Antiretroviral; AZT: Zidovudine; BD: Becton Dickinson; CCR5: C-C chemokine receptor type 5; CD3: Cluster of differentiation 3; CD3: Cluster of differentiation 4; CD8: Cluster of differentiation 8; CIRCB: Chantal BIYA International Reference for research on HIV/AIDS prevention and management; CRF: Case reporting form; CRF: Circulating recombinant form; CXCR4: C-X-C motif chemokine receptor type 4; DNA: 2'deoxy-ribose nucleic acid; DRM: Drug resistance mutation; EWl: Early warning indicators; FACS: Fluorescent activated cell sorting; GRT: genotypic resistance testing; HIV: Human immunodeficiency virus; HIVdb: HIV database; HIVDR: HIV drug resistance; IC: Interval confidence; ID: Identification; LPV/r: ritonavir-boosted lopinavir; LTFU: Lost to follow-up; M0: Month 0; M12: Month 12; M6: Month 6; NNRTI: Non-nucleoside reverse-transcriptase inhibitor; NRTI: Nucleoside reversetranscriptase inhibitor; NVP: Nevirapine; PCR: Polymerase chain reaction; PMTCT: Prevention of mother-to-child transmission of HIV; PR-RT: Proteasereverse transcriptase; PVL: Plasma viral load; RLS: Resource-limited settings; RNA: Ribose nucleic acid; RT: Reverse transcriptase; RTI: Reverse transcriptase inhibitor; RTPCR: Reverse transcriptase polymerase chain reaction: SDC: Supplementary digital content; SSA: Sub-Saharan Africa; VF: Virological failure; WHO: World Health Organisation

\section{Acknowledgements}

We are grateful to Dr. Serge Clotiare Billong of the National AIDS Control Committee of Cameroon, for providing information on HIV-infected adolescents in the study settings for utility in the sampling procedure and site selection. We thank the local clinicians and program mangers who provided their comments for the better design of the study protocol.

\section{Authors' contributions}

JF, MMS, DT, AN, VC and CFP: initiated the study protocol; AENN, PKN, NK, CK, AE and SMS revised the study protocol; All the authors: approved the final version of the manuscript.

\section{Funding}

The European and Developing Countries Clinical Trial Partnership (EDCTP), under the Career Development Fellowship (CDF) - Training Mobility Action (TMA) number 1027

Role of the funder: The study protocol was peer reviewed by the funding body. The funder has no role in the design, implementation, analysis and reporting of the study findings.

\section{Availability of data and materials}

Not applicable.

\section{Ethics approval and consent to participate}

The present study will be conducted according to the declarations of Helsinki on ethical principles for medical research involving human subjects (http:// www.wma.net/en/30publications/10policies/b3/). In this line, ethical clearance has been obtained from the Cameroon National Ethics Committee for Research on Human Health in Cameroon (http://www.cameroon-ethics.cm/fr/ quisommesnous): reference number N²018/01/981/CE/CNERSH/SP. After an informed notice on the study, a written informed will be obtained from legal guardian, and a written assent will also be obtained from the participating ADLHIV, without any coercion. Privacy and confidentiality will be ensured, through the use of unique identifiers and a protected database, to protect personal information for participants. Participants will be free to deliberately leave the study at any time, without any effect on their routine monitoring at the study clinic. Phlebotomy will be non-invasive (venipuncture) and will be performed by qualified staffs. All laboratory results generated in the course of the study, including GRT, will be used for the selection of most effective ARV drugs available in the national guidelines of Cameroon (first-, second- and third-line regimens). Our research findings will be communicated for improved management and monitoring of the target population. Study information sheets and informed consents are provided as SDG-2.

\section{Consent for publication}

Not applicable.

\section{Competing interests}

The authors declare that they have no competing interests.

\section{Author details}

'Chantal BIYA International Reference Centre for research on HIV/AIDS prevention and management (CIRCB), Yaoundé, Cameroon. ${ }^{2}$ Faculty of Medicine and Biomedical Sciences (FMSB), University of Yaoundé I, Yaoundé, Cameroon. ${ }^{3}$ National HIV Drug Resistance Working Group (HIVDRWG), 
Ministry of Public Health, Yaoundé, Cameroon. ${ }^{4}$ University of Rome Tor Vergata (UTV), Rome, Italy. ${ }^{5}$ National Social Welfare Hospital (NSWH), Yaoundé, Cameroon. ${ }^{6}$ Mother-Child Centre of the Chantal BIYA's foundation (MCC-CBF), Yaoundé, Cameroon. 'University Health Centre (UHC), Yaoundé, Cameroon. ${ }^{8}$ Mfou District Hospital (Mf.DH), Mfou, Cameroon. ${ }^{9}$ Mbalmayo District Hospital (Mb.DH), Mbalmayo, Cameroon. ${ }^{10}$ University of Milan (UM), Milan, Italy.

\section{Received: 29 April 2019 Accepted: 25 June 2019}

Published online: 05 July 2019

\section{References}

1. Joint United Nations Programme on HIV/AIDS. Fact sheet 2015. Geneva: UNAIDS; 2015 [cited 2016 Jan 15]. Available from: http:// http://www.unaids. org/sites/default/files/media_asset/20150901_FactSheet_2015_en.pdf.

2. World Health Organisation. Meeting report on HIV/AIDS: Paediatric ARV drug optimization 2. Geneva: World Health Organisation; 2014 [cited 2015 Jun 15]. Available from: http://www.who.int/hiv/pub/meetingreports/ paediatric-arv-optimization/en/.

3. Centers for Disease Control and Prevention. HIV surveillance report. Atlanta: Centers for Disease Control and Prevention; 2011 [cited 2015 Jun 15]. Available from: http://www.cdc.gov/hiv/topics/surveillance/resources/ reports/.

4. Joint United Nations Programme on HIV/AIDS. A progress report on the global plan towards the elimination of new HIV infections among children by 2015 and keeping their mothers alive. Geneva: UNAIDS; 2012 [cited 2015 Jun 15]. http://www.zero-hiv.dreamhosters.com/wp-content/uploads/2012/ 08/UNAIDS_ProgressReportGlobalPlan_FINAL_July17_Web.pdf.

5. Joint United Nations Programme on HIV/AIDS. The Gap Report. Geneva: UNAIDS; 2014 [cited 2015 Jun 15]. Available from: http://www.unaids.org/ en/resources/documents/2014/name,97466,en.asp.

6. Bekker LG, Hosek S. HIV and adolescents: focus on young key populations. J Int AIDS Soc. 2015;18(2 Suppl 1):20076.

7. Fish R, Judd A, Jungmann E, O'Leary C, Foster C. HIV young persons network (HYPNet). Mortality in perinatally HIV-infected young people in England following transition to adult care: an HIV young persons network (HYPNet) audit. HIV Med. 2014;15(4):239-44.

8. World Health Organisation. Consolidated guidelines on the use of antiretroviral drugs for treating and preventing HIV infection: recommendations for a public health approach. Geneva: World Health Organisation; 2013 [cited 2015 Jun 15]. Available from: http://www.who.int/ hiv/pub/guidelines/arv2013/en/.

9. PENPACT-1 (PENTA 9/PACTG 390) Study Team. First-line antiretroviral therapy with a protease inhibitor versus nonnucleoside reverse transcriptase inhibitor and switch at higher versus low viral load in HIV-infected children: an open-label, randomised phase 2/3 trial. Lancet Infect Dis. 2011;11:273-83. https://doi.org/10.1016/S1473-3099(10)70313-3.

10. World Health Organisation. HIV drug resistance report 2012. Geneva: World Health Organisation; 2012 [cited 2015 Jun 15]. Available from: http://www. who.int/hiv/pub/drugresistance/report2012/en/.

11. Chakanyuka-Musanhu CC, Penazzato M, Apollo T, Dzangare J, MtapuriZinyowera S, Mugurungi $\mathrm{O}$, et al. World Health Organization HIV drug resistance surveillance in children less than 18 months newly diagnosed with HIV in Zimbabwe. Paper presented at: The $7^{\text {th }}$ International AIDS Society Conference on HIV Pathogenesis, Treatment and Prevention; 2013 June 30 July 3; Kuala Lumpur, Malaysia. http://pag.ias2013.org/Abstracts.aspx?AID=2198

12. Paredes R, Marconi VC, Lockman S, Abrams EJ, Kuhn L. Impact of antiretroviral drugs in pregnant women and their children in Africa: HIV resistance and treatment outcomes. J Infect Dis. 2013:207(Suppl 2):S93-100. https://doi.org/10.1093/infdis/jit110.

13. Ciaranello AL, Doherty K, Penazzato M, Lindsey JC, Harrison L, Kelly K, et al. Cost-effectiveness of first-line antiretroviral therapy for HIV-infected African children less than 3 years of age. AIDS. 2015;29(10):1247-59. https://doi.org/ 10.1097/QAD.0000000000000672.

14. World Health Organisation. Antiretroviral therapy for HIV infection in infants and children: towards universal access recommendations for a public health approach: 2010 revision. Geneva: World Health Organisation; 2010. http:// www.ncbi.n/m.nih.gov/books/NBK138576/

15. Binagwaho A, Nutt CT, Nsanzimana S, Wagner CM, Mukherjee JS. Children and adolescents with HIV. Lancet Infect Dis. 2013;13(8):654. https://doi.org/ 10.1016/S1473-3099(13)70188-9.
16. von Wyl V, Klimkait T, Yerly S, Nicca D, Furrer H, Cavassini M, et al. Adherence as a predictor of the development of class-specific resistance mutations: the Swiss HIV cohort study. PLoS One. 2013;8(10):e77691. https:// doi.org/10.1371/journal.pone.0077691.

17. Fokam J, Billong SC, Bissek AC, Kembou E, Milenge P, Abessouguie I, et al. Declining trends in early warning indicators for HIV drug resistance in Cameroon from 2008-2010: lessons and challenges for low-resource settings. BMC Public Health. 2013;13:308. https://doi.org/10.1186/1471-2458-13-308.

18. Fokam J, Salpini R, Santoro MM, Cento V, Perno CF, Colizzi V, et al. Drug resistance among drug-naive and first-line antiretroviral treatment-failing children in Cameroon. Pediatr Infect Dis J. 2011;30(12):1062-8. https://doi. org/10.1097/INF.0b013e31822db54c.

19. Kebe K, Thiam M, Diagne Gueye NR, Diop H, Dia A, Signate Sy H, et al. High rate of antiretroviral drug resistance mutations in HIV type 1-infected Senegalese children in virological failure on first-line treatment according to the World Health Organization guidelines. AIDS Res Hum Retrovir. 2013;29(2):242-9. https://doi.org/10.1089/aid.2011.0300.

20. Charpentier C, Gody JC, Mbitikon O, Moussa S, Matta M, Péré H, et al. Virological response and resistance profiles after 18 to 30 months of first- or second-/third-line antiretroviral treatment: a cross-sectional evaluation in HIV type 1-infected children living in the Central African Republic. AIDS Res Hum Retrovir. 2012;28(1):87-94. https://doi.org/10.1089/AID.2011.0035.

21. Technau KG, Schomaker M, Kuhn L, Moultrie H, Coovadia A, Eley B, et al. Virologic response in children treated with abacavir-compared with stavudine-based antiretroviral treatment: a south African multi-cohort analysis. Pediatr Infect Dis J. 2014;33(6):617-22. https://doi.org/10.1097/INF. 0000000000000222

22. Takou D, Fokam J, Teto G, Santoro MM, Ceccherini-Silberstein F, Nanfack AJ, et al. HIV-1 drug resistance testing is essential for heavily-treated patients switching from first- to second-line regimens in resource-limited settings: evidence from routine clinical practice in Cameroon. BMC Infect Dis. 2019; 19(246) https://doi.org/10.1186/s12879-019-3871-0.

23. Boerma RS, Boender TS, van Hensbroek MB, Rinke de Wit TF, Sigaloff KC. Sequencing paediatric antiretroviral therapy in the context of a public health approach. J Int AIDS Soc 2015;18(7 Suppl 6):20265. https://doi.org/10. 7448/IAS.18.7.20265.eCollection 2015.

24. Kityo C, Sigaloff KC, Boender ST, Kaudha E, Kayiwa J, Musiime V, et al. HIV drug resistance among children initiating first-line antiretroviral treatment (ART) in Uganda. AIDS Res Hum Retrovir. 2016; Jan 1. [Epub ahead of print].

25. Alteri C, Santoro MM, Abbate I, Rozera G, Bruselles A, Bartolini B, et al. 'Sentinel' mutations in standard population sequencing can predict the presence of HIV-1 reverse transcriptase major mutations detectable only by ultra-deep pyrosequencing. J Antimicrob Chemother. 2011;66(11):2615-23. https://doi.org/10.1093/jac/dkr354.

26. Fokam J, Bellocchi MC, Armenia D, Nanfack JN, Carioti L, Continenza F, et al. Next-generation sequencing provides an added value in determining drug resistance and viral tropism in Cameroonian HIV-1 vertically infected children. Medicine (Baltimore). 2018;97(13):e0176. https://doi.org/10.1097/ MD.0000000000010176

27. Nanfack AJ, Takou D, Fokam J, Salpini R, Santoro MM, Cappelli G, Baane M, Tetang MS, Eberle J, Gurtler L, and Ceccherini-Silberstein F, et al. HIV-1 Drug Susceptibility to Newer Second- and Third-Line Antiretroviral Regimens among Cameroonian Patients: A Cross-sectional Study. Submitted to Curr HIV Res: BSP-CHIVR-2016-424.

28. Takou D, Nanfack A, Fokam J, Salpini R, Torimiro J, Cappelli C, et al. Multirésistance du VIH aux Antirétroviraux et Profil de Susceptibilité aux Nouvelles Classes de Traitement Antirétroviral au Cameroun. Oral Presentation at AFRAVIH 2012: Centre International des Conférences de Genève (CICG) ; Génève Suisse.

29. Mbondji-Wonje C, Ragupathy V, Zhao J, Nanfack A, Lee S, Torimiro J, et al. Genotypic prediction of tropism of highly diverse HIV-1 strains from Cameroon. PLoS One. 2014;9(11):e112434. https://doi.org/10.1371/journal.pone.0112434.

30. Church JD, Huang W, Mwatha A, Toma J, Stawiski E, Donnell D, et al. HIV-1 tropism and survival in vertically infected Ugandan infants. J Infect Dis. 2008;197(10):1382-8. https://doi.org/10.1086/587492.

31. Nglazi MD, Kranzer K, Holele P, Kaplan R, Mark D, Jaspan H, et al. Treatment outcomes in HIV-infected adolescents attending a community-based antiretroviral therapy clinic in South Africa. BMC Infect Dis. 2012 Jan 25;12:21. https://doi.org/10.1186/1471-2334-12-21.

32. Santoro MM, Perno CF. HIV-1 genetic variability and clinical implications. ISRN Microbiol. 2013;17(2013):481314. https://doi.org/10.1155/2013/481314. 
33. Armenia D, Gori C, Di Carlo D, Bertoli A, Borghi V, Fabeni L, et al. Patients infected with CRF02_AG are more likely to experience virological rebound under first line $\mathrm{PI} / \mathrm{r}$ based HAART. Paper presented at: The $13^{\text {th }}$ European HIV \& Hepatitis Workshop; 2015 June 3 - 5; Barcelona, Spain. http://www. virology-education.com/wp-content/uploads/2014/11/13th-EU_program_ 2015_5-212.pdf.

34. Veras NM, Santoro MM, Gray RR, Tatem AJ, Lo Presti A, Olearo F, et al. Molecular epidemiology of HIV type 1 CRF02_AG in Cameroon and African patients living in Italy. AIDS Res Hum Retrovir. 2011;27(11):1173-82. https:// doi.org/10.1089/AID.2010.0333.

35. Ceccarelli L, Salpini R, Moudourou S, Cento V, Santoro MM, Fokam J, et al. Characterization of drug resistance mutations in naive and ART-treated patients infected with HIV-1 in Yaounde, Cameroon. J Med Virol. 2012;84(5):721-7. https://doi.org/10.1002/jmv.23244.

36. Billong SC, Fokam J, Aghokeng AF, Milenge P, Kembou E, Abessouguie I, et al. Population-based monitoring of emerging HIV-1 drug resistance on antiretroviral therapy and associated factors in a sentinel site in Cameroon: low levels of resistance but poor programmatic performance. PloS One. 2013: 26; (8):e72680. https://doi.org/10.1371/journal.pone.0072680.eCollection 2013.

37. Fokam J, Elat JB, Billong SC, Kembou E, Nkwescheu AS, Obam NM, et al. Monitoring HIV drug resistance early warning indicators in Cameroon: a study following the revised World Health Organization recommendations. PLoS One 2015 Jun 17;10(6):e0129210. https://doi.org/10.1371/journal.pone. 0129210.eCollection 2015.

38. Sharp ER, Willberg CB, Kuebler PJ, Abadi J, Fennelly GJ, Dobroszycki J, et al. Immunodominance of HIV-1 specific CD8+ T-cell responses is related to disease progression rate in vertically infected adolescents. PLoS One. 2011;6(7):e21135. https://doi.org/10.1371/journal.pone.0021135.

39. République du Cameroun, Institut National de la Statistique. Ministère de l'Économie de la Planification et de l'Aménagement du Territoire?Ministère de la Santé Publique. Enquête Démographique de Santé et a indicateurs multiples (EDS-MICS 2011); Yaundé: September 2012.

40. Saounde Temgoua EM, Nkenfou CN, Zoung-Kanyi Bissek AC, Fokam J, Billong SC, Sosso SM, et al. HIV-1 early infant diagnosis is an effective Indicator of the prevention of mother-to-child transmission program performance: experience from Cameroon. Curr HIV Res. 2015;13(4):286-91.

41. Comité Nationale de Lutte contre le SIDA. Rapport d'Evaluation de la file active des PWIH au Camer- oun. Yaoundé; 2014.

42. Comité Nationale de Lutte contre le SIDA. Plan strategique nationale de lute contre le VIH, le SIDA et les IST /2011-2015. Yaoundé: December 2010.

43. Fokam J, Salpini R, Santoro MM, Cento V, D'Arrigo R, Gori C, et al. Performance evaluation of an in-house human immunodeficiency virus type-1 protease-reverse transcriptase genotyping assay in Cameroon. Arch Virol. 2011;156(7):1235-43. https://doi.org/10.1007/s00705-011-0982-3.

44. Gardner EM, Burman WJ, Steiner JF, Anderson PL, Bangsberg DR. Antiretroviral medication adherence and the development of class-specific antiretroviral resistance. AIDS. 2009;23(9):1035-46. https://doi.org/10.1097/ QAD.0b013e32832ba8ec

45. Santoro MM, Fabeni L, Armenia D, Alteri C, Di Pinto D, Forbici F, et al. Reliability and clinical relevance of the HIV-1 drug resistance test in patients with low viremia levels. Clin Infect Dis. 2014;58(8):1156-64. https://doi.org/ 10.1093/cid/ciu020.

46. Fokam J, Billong SC, Jogue F, Moyo Tetang Ndiang S, Nga Motaze AC, Paul KN, Njom Nlend AE. Immuno-virological response and associated factors amongst HIV-1 vertically infected adolescents in Yaoundé-Cameroon. PLoS One 2017;12(11):e0187566. doi: https://doi.org/10.1371/journal.pone. 0187566.eCollection 2017.

\section{Publisher's Note}

Springer Nature remains neutral with regard to jurisdictional claims in published maps and institutional affiliations.

\section{Ready to submit your research? Choose BMC and benefit from}

- fast, convenient online submission

- thorough peer review by experienced researchers in your field

- rapid publication on acceptance

- support for research data, including large and complex data types

- gold Open Access which fosters wider collaboration and increased citations

- maximum visibility for your research: over $100 \mathrm{M}$ website views per year

At $\mathrm{BMC}$, research is always in progress.

Learn more biomedcentral.com/submissions 